\title{
Analgesia for the dressing of burns in children: a method using neuroleptanalgesia and Entonox
}

\author{
P. J. F. BASKETT \\ B.A., M.B., B.Ch., F.F.A., R.C.S. \\ United Bristol Hospitals and Frenchay Hospital, Bristol
}

\begin{abstract}
Summary
The use of neuroleptanalgesia combined with Entonox for burns dressing in children is described.

The combination has proved satisfactory on fortynine occasions.

There has been no evidence of respiratory depression.
\end{abstract}

IT was Smith \& Hollis at East Grinstead in 1966 who first described in the British literature the use of neuroleptanalgesia for the dressing of burns. They had considerable success with the method but, as might be expected, there was some respiratory depression in a number of cases if the opiate was given in sufficient dosage to provide full analgesia.

We repeated this work in Bristol in a series of twenty-seven children aged 9 months to 6 years with very similar results. We used dehydrobenzperidol in a dose of $0.1-0.2 \mathrm{mg} / \mathrm{kg}$ and phenoperidine in a dose ranging from 0.05 to $0.1 \mathrm{mg} / \mathrm{kg}$ (Fig. 1) given intravenously through an indwelling needle. In assessing the initial dose of phenoperidine the child's demeanour, general fitness and the extent of the procedure to be carried out were taken into consideration. Twelve cases required an additional increment of phenoperidine of $0.025 \mathrm{mg} / \mathrm{kg}$ during the procedure (Fig. 1).

Analgesia was highly satisfactory in twenty-five of the twenty-seven cases and partially satisfactory in the remaining two cases.

Serial blood pressure recordings could only be made in six of the patients because of the difficulty of finding an unburnt surface to apply the sphygmomanometer cuff to the arm. In these six patients a consistent but small fall in arterial pressure was noted, but in no case was the fall in the systolic pressure greater than $15 \mathrm{~mm}$ of mercury. The pulse rate tended to rise in most cases, but again the change was small, being no more than 20 beats/min in any patient.

The effect on respiration is shown in Fig. 2 which illustrates the percentage fall in respiratory rate from the resting values in this series of patients.

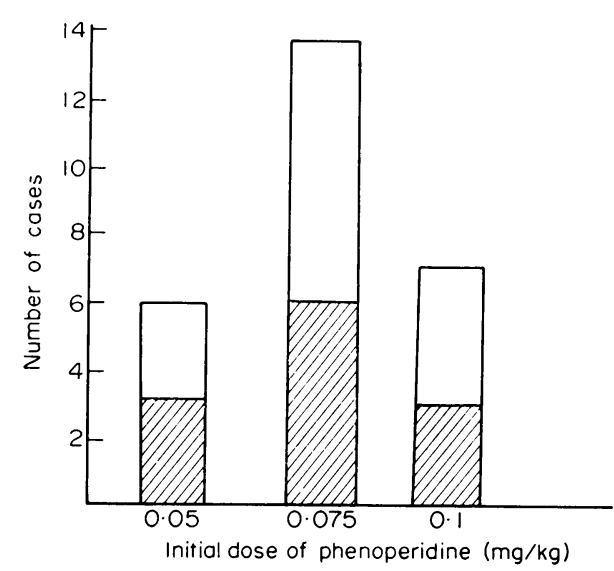

FIG. 1. Dose of phenoperidine required using neuroleptanalgesia alone. The shaded areas indicate cases needing a further dose of $0.025 \mathrm{mg} / \mathrm{kg}$.

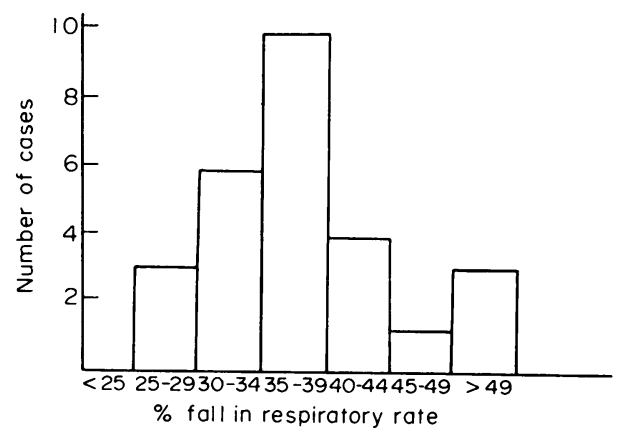

FIG. 2. Respiratory depression using neuroleptanalgesia alone.

In three cases out of the twenty-seven marked respiratory depression occurred, the respiratory rate falling by more than $40 \%$ of the resting rate and being accompanied by central cyanosis (Fig. 2). This was treated by ventilatory assistance using a self-inflating bag which was kept to hand for every case. On each occasion adequate spontaneous respiration returned within $10 \mathrm{~min}$ without resorting to the use of an opiate antagonist. These three cases 
were those who received an initial dose of phenoperidine of $0.1 \mathrm{mg} / \mathrm{kg}$.

It is therefore, apparent that there is a danger in some $10 \%$ of cases in using these drugs in full analgesic dosage unless competent respiratory assistance is always at hand. This eliminates the technique as a simple and foolproof method.

How then can we reduce the dose of phenoperidine to non-respiratory depressant levels and yet retain full analgesia for burns dressings?

Being interested in the more widespread use of nitrous oxide in hospital as an analgesic for minor procedures we decided to try a combination of neuroleptanalgesia and nitrous oxide. Nitrous oxide is one of the few potent analgesics which does not cause any respiratory depression and, although a $50 \%$ concentration alone is not always potent enough to provide full analgesia for the painful business of dressing burns, its performance is enormously enhanced by neuroleptanalgesia in quite modest and, therefore safe, doses. A $50 \%$ mixture of nitrous oxide and oxygen can be conveniently administered in a premixed state from a single cylinder (Entonox BOC) using a demand apparatus or a continuous flow device for patients with a burnt face (Baskett et al., 1969).

We have now used this combined method on forty-nine occasions. A similar dose of dehydrobenzperidol was given, followed by approximately half the dose of phenoperidine. After $3 \mathrm{~min}$ the mask was applied to the face and the gas mixture inhaled for a further 3-5 $\mathrm{min}$ before the procedure was begun.

So far, in this series of cases who have received nitrous oxide and neuroleptanalgesia, the procedure has been successful each time. Analgesia has been excellent and on one occasion was sufficient for taking skin for grafting. Nevertheless, the patient can be immediately woken up by calling his name after the mask is removed and can take nourishment within $2 \mathrm{hr}$.

With this combined technique there has been no clinical evidence of severe respiratory depression and the dose of phenoperidine has been reduced to $0.03-0.05 \mathrm{mg} / \mathrm{kg}$ (Fig. 3). This is well below the level of $0.1 \mathrm{mg} / \mathrm{kg}$ at which we had previously found respiratory depression. Figure 4 shows that no patient suffered a depression of respiratory rate of more than $33 \%$ from his resting value.

\section{Conclusions}

The combination of neuroleptanalgesia with a $50 \%$ mixture of nitrous oxide and oxygen can provide satisfactory and profound analgesia for burns dressing, so avoiding the dangerous side-effect of respiratory depression. Each agent enhances the other's good points and minimizes its deficiencies.

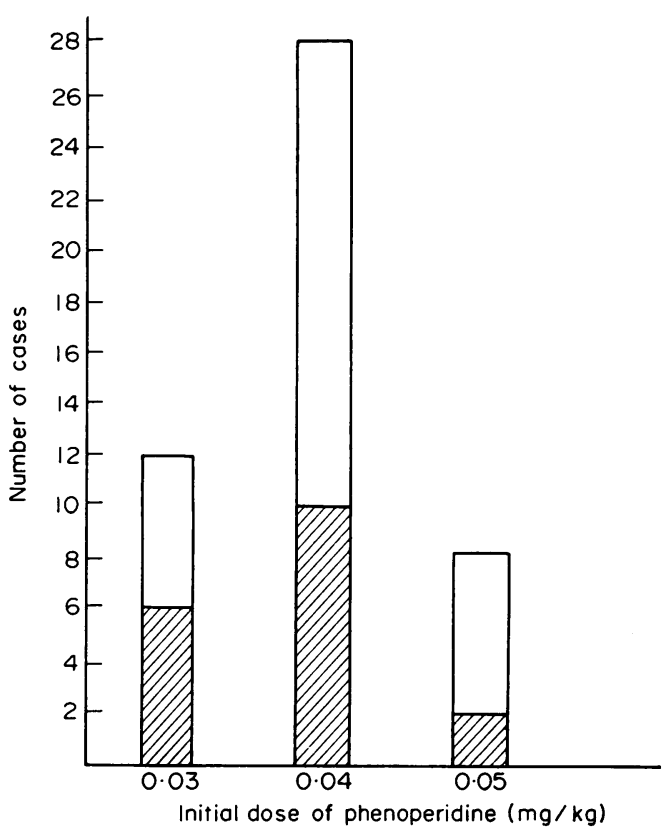

FIG. 3. Dose of phenoperidine required using neuroleptanalgesia and Entonox. The shaded areas indicate cases needing a further dose of $0.01 \mathrm{mg} / \mathrm{kg}$.

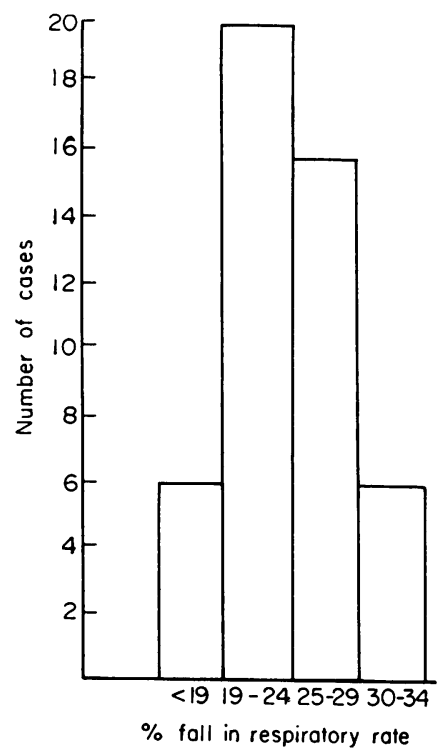

Fig. 4. Respiratory depression using neuroleptanalgesia and Entonox.

The technique can also be used for minor surgical, orthopaedic and radiological procedures and provides good conditions for patient and surgeon alike in the many minor, but nevertheless painful and distressing manoeuvres which are done in the average 
district general hospital every day but which do not warrant a full general anaesthetic in the accepted sense of the word.

(A short film showing the use of the combined technique was then shown.)

\section{References}

Smith, Barry G. \& Hollis, D.A. (1966) The use of dehydrobenzperidol and phenoperidine for repeated burns dressings. British Journal of Anaesthesia, 38, 471.

BasketT, P.J.F., Hyland, J., Deane, M. \& Wray, G. (1969) Analgesia for burns dressing in children. British Journal of Anaesthesia, 41, 684.

\section{Discussion}

Dr Russell M. Davies: May I start with two simple questions. First of all, are these patients prepared in any way?

DR BASKETT: We do not starve them beforehand.

DR Russell M. Davies: And how soon, for example, would that child have been able to have taken food?

DR BASKETT: I should think after a couple of hours. It is not as quick as methoxyflurane. As you probably know, that film was made more than 2 years ago. We have reduced the dose of dioperidol since then. The figure was $0.3 \mathrm{mg}$; certainly now $0.2 \mathrm{mg}$ is adequate. We started off with larger doses being keen to make sure that they did not feel any pain, and we have cut down now.

DR Russell M. Davies: Certainly $2 \mathrm{hr}$ is a vast reduction on the sort of times we were getting. It is impressive.

DR A. W. EDRIDGE (East Grinstead): What criteria did you use to determine your initial doses $-0.5 \mathrm{mg}, 0.75 \mathrm{mg}$, $1.0 \mathrm{mg}$, and so forth?

DR BASKETT: Guesswork initially, and then it came from there. We started with, I think, about $0.5 \mathrm{mg}$. I always went on the premise of adding a bit.

DR HowIE: I wonder whether, in our anxiety to provide the burnt patient with adequate analgesia while avoiding the hazards and the necessary precautions we must take for general anaesthesia, we are not beginning to create for ourselves a field where we are not quite sure where profound analgesia stops and anaesthesia commences. This is the reaction of one of my colleagues in Edinburgh. I would say that your patients under excellent analgesia were more deeply anaesthetized than mine are under what I consider light anaesthesia.

DR BASKETT: You are getting into terminology here. You are thinking of a muscle relaxant technique.

DR HowIE: No, I am not. If we are going to call something general anaesthesia we require to take precautions. I would have thought that $50 \%$ nitrous oxide plus oxygen for many forms of surgery is what we call anaesthesia.

DR BASKETT: Yes; call it what you will, but the object is to relieve pain, which is analgesia. I suppose some of these patients might be termed anaesthetized. If you shout at them some of them may come round, but not as long as you keep the nitrous oxide on usually. If you take the mask off and miss just a few breaths of nitrous oxide, they will come round very quickly. You are worried about the question of food beforehand?

DR HowIE: Yes.

DR BASKETT: We certainly always are prepared for them to vomit or regurgitate. No-one has done so yet out of more than 100 patients. You can say we have been lucky. People can vomit even though you do take precautions. We considered it an acceptable risk.

DR BuSH: May I ask two questions? Can we be a bit more specific about this business of the patients being prepared? You said they were not prepared. Does that mean that you allow them to eat and drink up to the time you give the drug, or do you stop them having food and drink for a specific number of hours beforehand?

Also may I ask if you have any idea of the incidence of patients who you would consider to have lost their laryngeal reflex during the procedure?

DR BASKETT: As regards preparation, we did not ever do this within an hour of feeding. We tried to do it in between feedings -in the middle of the morning or the middle of the afternoon. So to that extent there was some preparation, probably $2 \mathrm{hr}$ before.

The second part of the question was about laryngeal reflexes. I do not really know the answer. I think some certainly had impaired reflexes but it is a job to say who. The jaw tone was good and it would have been difficult to introduce anything into the mouth without some reaction.

DR BUSH: I am suggesting that this is perhaps a criterion for distinguishing between analgesia and anaesthesia.

DR BASKETT: Yes, but precisely what test one would do, I do not know.

DR A. HATfield (New Zealand): How would you modify your technique if a child had been burned on the face?

DR BASKETT: We use a sterile mask. That is about the only modification. With the initial dose, generally if you put the mask on they accept it. We have done this quite often with burnt patients.

DR HATFIELD: And if they have to dress the faces?

DR BASKETT: I do not think we have really run into this. We have not had to do a major desloughing of the patient's nose and mouth area.

DR HATFIELD: Would your technique be sufficient if a graft was necessary for the procedure?

DR BASKetT: Put it this way: We have taken skin on occasions with no problem and without any disturbance to the child, but I would not bet on it every time. I would not think you could say 'This is a good technique for taking skin'. You might get away with it, but it is asking a lot.

DR MiLler (Dundee): With regard to these large doses which you administered to the older children, did they express any unwillingness to repeat the procedure? Did this have any bad effects, or do you think this may have been mașked by giving the nitrous oxide and oxygen? 
DR BASKETT: I think the latter is a very true statement. We expected to see some problems. I cannot say that every child was delighted to see me again, but they accepted it and did not make any fuss. I did not have any bad reports from the nurses, and I did particularly ask them to tell me if a child complained of bad dreams or unpleasant side-effects. It may be that the nitrous oxide may have masked any bad effects.

Dr Miller: Up to what age?

DR BASKETT: 11 years was the oldest.

DR Russell M. DAVIES: Surely out of this discussion is coming one of the key points in the anaesthetist's work in handling the burned patient; and that is that so often we have to compromise between various requirements. Does one put a mask on the face? Is it anaesthesia or analgesia? Surely we have to be quite clear so often, what end we are achieving, and then we have to give and take on various factors in order to achieve that end. Presumably with a burnt face and slough on it, ideally it would be desirable not to put a mask on, but in order to achieve analgesia this is necessary. If analgesia swings into anaesthesia, as long as the patient does not vomit and can eat fairly soon thereafter the proof is in the pudding-which we hope the patient keeps down. Surely this is one of the problems-how to intubate a patient and where to intubate a patient. The problem is so often one of reconciling a number of differing and conflicting needs. Surely this is one of the things that this discussion has brought out.

DR J. MurRay (East Grinstead): I would like to know whether you have tried any of the newer analgesics in the same group like Fentanyl, or the experimental ones.

DR BASKeTT: I have tried Fentanyl which I think may well be better. It certainly lasts for a shorter time, which has some advantages and some disadvantages. It is perhaps good to have a bit of analgesia continuing afterwards as long as consciousness and co-operation are retained. I have not any figures for Fentanyl here but we have used it, I think, in about fifteen or twenty cases. I am convinced of its worth. The dosage calculation is a bit more difficult. We reckoned that Fentanyl was ten times more potent than phenoperedine which was about right, but it was not right for everyone. I think the Fentanyl was less potent than we thought.

DR W. N. Rollason: May I make a general comment and not a specific one? Are we right as anaesthetists almost always to base our intravenous drugs on body weight? Is it not more scientific to inject an intravenous drug very slowly and titrate it, taking the individual patient's response?

DR BASKETT: I think this is obviously right, except that you have got to have some sort of idea of what signs you are looking for. There can be no criticism when you have given enough. How you assess when you have given enough is perhaps more difficult! I think one has to have some idea beforehand.

Dr Russell M. Davies: Could I comment on both question and answer? I wonder whether Dr Baskett could help me on this one. We found that we always titrated the phenoperedine into the patient on the first administration. Thereafter it struck us that each patient was his own control, and the amount required by each patient at subsequent dressings seemed to be remarkably constant for that patient. We titrated first, and then clung hopefully to this thesis that they seemed to provide their own standard.

DR BASKeTt: Yes, that has been our experience too. We thought that it might go up each time, but it did not. Could I ask Dr Rollason what criteria he would have for saying when the right dose has been given?

DR Rollason: I personally do not use neuroleptanaesthesia very much, but $I$ do use intravenous diazepam in dental work quite a lot and it is very easy to titrate a dose of this drug to a patient's response. I would have thought that one could find some evidence of change in respiratory rate or change in voice or some sign to indicate that you had reached the right depth, provided-and I think this is the vital point-you inject the drug very very slowly. I think anaesthetists in general inject their drugs intravenously far too rapidly. We have got to learn to give our intravenous drugs very slowly and learn to titrate the dose to the individual.

DR Russell M. Davies: It is a contentious statement, if I may say so.

DR R. BURTLES: Over the years we have seen the most remarkable changes. I can remember when thiopentone was put into a $10-\mathrm{ml}$ ampoule and mixed with $10 \mathrm{ml}$ of water and you injected the lot. It swung to $5 \%$, and then it swung to $2 \frac{1}{2} \%$ and now we are getting to the point where I am wondering whether we sometimes forget to put the thiopentone into the water. In other words, unless we have got an end point that we are looking for, we just do not do this. I think, in my limited experience of this, that we are now left without anything definite to work on. Although in principle I am very much inclined to agree with what Dr Rollason says, I think in practice it is much more difficult.

DR RUSSell M. Davies: Surely it depends largely on the rate of elimination of the drug. One can give $0.5 \mathrm{~g}$ of pentothal so slowly that the patient does not go to sleep.

DR Rollason: I am not so sure about this. I have been injecting another drug which is eliminated more rapidly than thiopentone; I am now referring to propanidid and I inject this at a rate no faster than $1 \mathrm{ml}$ in $20 \mathrm{sec}$, and I have yet to find, if you give enough, any patient failing to go to sleep.

DR BASKeTt: Do you find that you have to give more of a total dose?

DR Rollason: I am not sure. I have not assessed this. But what $I$ am certain about is that it is safer.

DR Bush: As regards children, it is absolutely right to support Dr Baskett's assertion. You must have some indication of what it is you are giving a particular patient. It is reasonable enough to suggest that you should base it on a body weight basis, particularly as the body weight in children is very close to the mean body mass, and this is what we are really concerned with. It is absolutely right, too, that one should assess this dose on what happens to it in a particular patient, but you must have an indication of the sort of drug dose that you are going to give, and, as Dr Baskett showed, he topped this up as necessary to reach a certain criterion for his particular drug. There are other drugs, of course, where you know that you are going to produce a $100 \%$ effect. That means that you can quite easily calculate what dose it will be that in $100 \%$ of 
cases will produce your end point. Therefore, I think it is relatively easy in these cases to have a dose on a body weight basis.

DR Rollason: I accept the fact that in the young child there is a much greater case for basing the drug dose on body weight but I do not think this applies one iota to the adult. I have noticed when one has compared what has been a pre-judged dose on body weight and what one has assessed the patient required on a titration principle, that the divergence has been very marked. You have to give some patients more than you would think on body weight, and to an equal number of patients you would give far less than you would think should be given on a body weight basis.
MR J. Cobbetr (East Grinstead): I enjoyed that technique very much indeed. It looked superb. May I make two small criticisms? First, presumably you would never entrust this to lay hands-since we were talking about manpower earlier. Second, you have lost the co-operation of the patient, which can be very helpful.

DR BASKeTT. Yes, I would accept the first point. I agree that it is not a technique for the non-anaesthetist. On the second point-our experience with neuroleptanalgesia alone was that if we gave enough of it to make them pain-free, all co-operation went. Of course, this has been with children, who are much more easily manhandled. If an adult can hold up his own leg, it is perhaps useful. In children, it does not matter quite so much. 